\title{
Economia de água e energia em projetos de irrigação suplementar no Estado de Minas Gerais
}

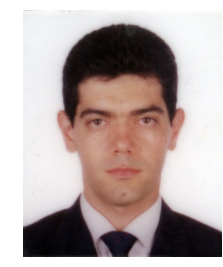

\author{
Roberto A. de Faria ${ }^{1}$, Antônio A. Soares², Gilberto C. Sediyama² \& Carlos A. Á. S. Ribeiro ${ }^{3}$ \\ 1 DER/UFV. CEP 36571-000, Viçosa, MG. Fone (31) 3899-2214, E-mail: ds26875@correio.ufv.br (Foto) \\ 2 DEA/UFV. Fone: (31) 3899-2730, Fax: (31) 3899-2735. E-mail: aasoares@mail.ufv.br e sediyama@mail.ufv.br \\ 3 DEF/UFV. Fone: (31) 3899-1210,Fax: (31) 3899-2478. E-mail: cribeiro@mail.ufv.br
}

Protocolo $017-9 / 2 / 2001$

\begin{abstract}
Resumo: Dados climatológicos cedidos pelo Instituto Nacional de Meteorologia (INMET) e pela Agência Nacional de Energia Elétrica (ANEEL), foram usados em um modelo de balanço hídrico associado a um sistema de informações geográficas, para gerar mapas temáticos do Estado de Minas Gerais apresentando as classes de demanda de irrigação real necessária (demanda total) e de irrigação suplementar real necessária (demanda suplementar) para a cultura do milho (Zea mays L). Gerou-se, um mapa, no qual se registraram as diferenças entre a demanda de irrigação total e a suplementar, para verificar a conveniência de incluir ou não a contribuição das precipitações em um projeto de irrigação localizado no Estado de Minas Gerais, e outro mapa temático em que se estimou o custo de não se considerar a precipitação no manejo do projeto.
\end{abstract}

Palavras-chave: irrigação suplementar, SIG, custo

\section{Water and energy savings in supplemental irrigation projects in Minas Gerais State, Brazil}

\begin{abstract}
Climatologic data from the 'Instituto Nacional de Meteorologia' (INMET) and 'Agência Nacional de Energia Elétrica' (ANEEL) were used in the water balance model associated with a geographical information system in order to generate a number of thematic maps of Minas Gerais State regarding the classes of the true irrigation demand (total demand) and the demand for actual supplemental irrigation (supplemental demand) for corn crop (Zea mays L). A map was generated, where the differences between the total irrigation demand and the supplemental one were registered to verify the usefulness of including the contribution of the rainfall in an irrigation project for Minas Gerais State, besides another thematic map in which the cost of not considering the effect of rainfall in the project management was included.
\end{abstract}

Key words: supplemental irrigation, SIG, cost

\section{INTRODUÇÃO}

Como tecnologia indispensável para aumentar a produtividade e atender a uma demanda crescente por alimentos, a expansão da área irrigada tem intensificado a concorrência no uso da água com o setor energético, a indústria e o consumo doméstico. Como a água é um recurso natural limitado e estratégico para o crescimento econômico da nação, sua racionalização é de suma importância.

A análise de registros históricos de dados climáticos permite prever a precipitação e estimar a evapotranspiração que, juntamente com a capacidade de retenção de água do solo, torna possível estimar-se o balanço de água na zona radicular das culturas e as demandas totais (do ciclo) e diária de irrigação suplementar real necessária, segundo a época de plantio da cultura.

Devido às dificuldades de acesso às informações meteorológicas, na análise de características de distribuição das precipitações pluviais e na complexidade de seu processamento na simulação de um sistema, os projetos são, em sua maioria, dimensionados em termos de irrigação total (sem se considerar a contribuição das chuvas). Atendendo às necessidades nos períodos críticos de escassez de água para os cultivos e sem levar em conta as precipitações naturais, o projetista tem sido conduzido a superdimensionar os sistemas de irrigação onerando, assim, o custo da instalação por unidade de área; neste sentido e se considerando a contribuição natural das chuvas, existem basicamente duas formas de se otimizar os sistemas de irrigação: no projeto e no manejo. No primeiro caso, a diminuição na demanda máxima de irrigação proporciona redução na dimen-são do sistema (potência de motobomba, capacidade dos transformadores, diâmetro das tubulações) reduzindo-se, desta forma, os custos de instalação, enquanto no segundo caso se deve fazer o manejo de irrigação no sentido de maximizar o uso da água de chuva e, conseqüentemente, minimizar a quantidade de água aplicada via 
irrigação, proporcionando economia de água e energia, reduzindo os custos de manutenção.

Por não adotar um método de controle de irrigação, usualmente o produtor rural irriga em excesso, temendo que a cultura sofra estresse hídrico, que poderia comprometer a produção. Este excesso tem, como conseqüência, o desperdício de energia em bombeamento desnecessário de água. Para exemplificar, um milímetro de lâmina excedente em uma área irrigada por um pivô central de 100 ha, representa a condução desnecessária de um milhão de litros de água, que consome, em média, $400 \mathrm{kWh}$ de energia elétrica. É necessário, portanto, manejar racionalmente a irrigação para que se evite o mau uso de fatores de produção tão essenciais como água e energia.

Além dos pontos já considerados, o projetista, ao elaborar projetos de irrigação, geralmente utiliza informações climatológicas de locais muitas vezes distantes da área a ser irrigada, procedimento adotado em razão da falta de informações climatológicas espacializadas, o que o leva a considerar que o valor medido na estação meteorológica representa uma área homogênea em torno dela, o que, normalmente, não é verdade em áreas com grandes variações climáticas e topográficas. Essas variações afetam as necessidades hídricas das culturas e devem ser consideradas ao se planejar a irrigação suplementar. Com o objetivo de quantificar essas variações, Hashmi et al. (1995) modelaram espacialmente, empregando técnicas de interpolação disponíveis em um sistema de informação geográfica, a variabilidade dos parâmetros usados para estimar a evapotranspiração regional e concluíram que a versatilidade do sistema, ao considerarem a variabilidade espacial e temporal proporciona aos pesquisadores poderosa ferramenta para análise espacial.

O presente trabalho teve por objetivo contabilizar, mediante técnicas de um Sistema de Informação Geográfica - SIG, a contribuição das chuvas na dotação de água dos projetos de irrigação no Estado de Minas Gerais elaborados para a cultura do milho e o custo de não considerá-la.

\section{MATERIAL E MÉTODOS}

Os dados climatológicos utilizados no presente trabalho foram cedidos pelo INMET (Instituto Nacional de Meteorologia) e pela ANEEL (Agência Nacional de Energia Elétrica). As estações da ANEEL apresentavam apenas dados de pluviometria. O período adotado foi de 1961 a 1978 , e as estações selecionadas foram aquelas que apresentavam série histórica mínima de 10 anos para precipitação e de cinco anos para evapotranspiração.

Das 85 estações operadas pelo INMET a que se teve acesso, apenas 35 apresentavam séries históricas mínimas de 10 anos (disponibilizando pluviometria e parâmetros para estimativa da evapotranspiração) e 16 de 5 a 10 anos. Portanto, para a estimativa da evapotranspiração em todo o Estado de Minas, contou-se com 51 estações daquele Instituto.

As estações da ANEEL não apresentavam dados necessários à estimativa da evapotranspiração, parâmetro essencial ao modelo descrito, mas apenas pluviometria, razão pela qual, para as localidades referentes as 62 estações pluviométricas selecionadas, utilizaram-se os dados das estações do INMET mais próximas.
Nas regiões montanhosas como o Sul de Minas e a Zona da Mata, a distância entre as estações meteorológicas do INMET e da ANEEL não poderia ultrapassar $20 \mathrm{~km}$, a fim de aproveitar, como dados locais, os valores de evapotranspiração da estação do INMET vizinha, enquanto em outras regiões mais planas, como o Norte de Minas, essa distância foi ampliada em até $100 \mathrm{~km}$.

Para simulação do balanço de água no solo a partir dos dados climatológicos, desenvolveu-se um software em Delphi 1.0. No cálculo desse balanço, utilizou-se a metodologia apresentada em Souza (1993) desenvolvida em termos de déficit de água no solo e tendo como referência a umidade à capacidade de campo; a diferença é que, no presente estudo, a precipitação dependente foi estimada a partir da distribuição gama de probabilidade, descrita em Assis et al. (1996) em nível de 75\% de probabilidade, e a evapotranspiração de referência (ETo) foi estimada usandose o modelo de Penamn-Monteith, padrão FAO 1991, conforme Smith (1991). A evapotranspiração foi calculada em cada período, empregando-se o coeficiente da cultura proposto por Doorenbos \& Pruitt (1977) e o coeficiente de umidade do solo apresentado por Bernardo (1995). O número de dias de cada estádio do milho foi estimado conforme a faixa de variação da temperatura do ar, segundo metodologia de Coelho (1978).

Por este modelo, analisaram-se os diferentes turnos de rega ao longo do ciclo e se elegeu o menor turno de rega como parâmetro fixo para fazer nova simulação de irrigação na data de plantio correspondente. Para cada ciclo simulado, o programa elege a lâmina máxima de irrigação suplementar real necessária utilizando-se turno de rega fixo. Dividindo-se seu valor pelo turno de rega, tem-se a demanda máxima diária de irrigação suplementar real necessária.

As simulações referem-se a datas de plantio diariamente, ao longo de todo o ano, estimando-se as demandas máximas diárias de irrigação suplementar real necessária para cada ciclo da cultura. Dentre as demandas máximas de cada data de plantio ao longo do ano, selecionou-se o valor máximo de cada estação meteorológica sendo, a seguir, realizada a espacialização desta variável no Estado de Minas Gerais, mediante o emprego de técnicas do Sistema de Informações Geográficas-SIG. Repetiuse o procedimento considerando-se três tipos de solo: de textura grossa, média e fina, respectivamente, com disponibilidade total de água (DTA) no solo de 0,$6 ; 1,2$ e 1,8 mm de água por $\mathrm{cm}$ de solo (Bernardo, 1995).

O modelo foi utilizado considerando-se a contribuição das chuvas na estimativa da demanda máxima diária de irrigação suplementar real necessária (irrigação suplementar) enquanto na estimativa da demanda máxima de irrigação (irrigação total) se desprezou a precipitação no balanço de água no solo.

Para a regionalização das demandas de irrigação real necessária e de irrigação suplementar real necessária do milho e, ainda, para a elaboração dos mapas temáticos representando a diferença entre elas, utilizou-se o software de informação geográfica Idrisi, desenvolvido pelo Departamento de Geografia da Clark University, EUA, disponível no Departamento de Engenharia Agrícola da Universidade Federal de Viçosa.

Os mapas vetoriais das mesorregiões e do contorno do Estado de Minas Gerais foram obtidos por meio da importação de arquivos disponíveis no "site" Geominas (www.geominas.mg.gov.br) de responsabilidade da Secretaria 
de Estado da Casa Civil do Governo de Minas Gerais. Esses mapas foram elaborados pela Companhia de Processamento de Dados do Estado de Minas Gerais (PRODEMGE), a partir do mapa geopolítico de Minas Gerais, escala 1:1.500.000 (sistema de referência latitude/longitude) com o software MapInfo, que estão em arquivos com extensão DXF convertidos em módulo específico do Idrisi para imagens compatíveis com o sistema utilizado (DXF/IDRISI “Conversion Module").

Criou-se um mapa de 948 linhas por 1.196 colunas, com tamanho de célula de aproximadamente $1 \times 1 \mathrm{~km}$ e se converteu a imagem do contorno de Minas Gerais, de estrutura vetorial para estrutura matricial; além disso, efetuou-se a interpolação dos valores pontuais georreferenciados das demandas de irrigação real necessária e de irrigação suplementar real necessária dos dias julianos respectivos da melhor época de plantio e distribuídos sobre o mapa de Minas, contidos em arquivos tipo ASCII e previamente criados por um editor de textos.

Enfim, nesta rotina utiliza-se um interpolador linear, em que o peso da célula a ser interpolada é dado por uma média ponderada que utiliza o peso dos pontos de controle mais próximos (definido pelo usuário) ponderados pelo inverso da distância, elevada a um expoente (definido pelo usuário), ou seja:

$$
\mathrm{G}_{\mathrm{i}}=\frac{\sum_{\mathrm{i}=1}^{\mathrm{n}}\left(\frac{\mathrm{x}_{\mathrm{i}}}{\mathrm{d}_{\mathrm{i}}{ }^{\mathrm{m}}}\right)}{\sum_{\mathrm{i}=1}^{\mathrm{n}}\left(\frac{1}{\mathrm{~d}_{\mathrm{i}}{ }^{\mathrm{m}}}\right)}
$$

em que:

$\mathrm{G}_{\mathrm{i}}$ - peso estimado no ponto interpolado

$\mathrm{x}_{\mathrm{i}} \quad$ - peso do i-ésimo ponto amostrado

$\mathrm{d}_{\mathrm{i}}$ - distância euclidiana do i-ésimo ponto amostrado $\mathrm{i}$ ao ponto interpolado

m - expoente da função distância

n - número de pontos amostrados

O interpolador do Idrisi trabalha com um raio de busca variável que pode utilizar os seis pontos amostrados mais próximos do ponto interpolado ou utilizar todos os pontos de controle (Eastman,1992). Aqui, optou-se por utilizar os seis pontos mais próximos e o expoente da função distância igual a 4 que, em testes preliminares, produziu melhores resultados para o caso em questão; em seguida e por meio da rotina de reclassificação (Reclass) geraram-se mapas temáticos do Estado de Minas Gerais contendo as classes de demanda de irrigação real necessária (demanda total) e de irrigação suplementar real necessária (demanda suplementar); para finalizar, utilizou-se o módulo "overlay" (operação de mapas com opção multiplicação) da imagem rasterizada de Minas Gerais com a imagem gerada pelo "reclass", exibindo o mapa final no módulo "display", com uma paleta de cores, definida pelo autor.

Produziu-se, a partir dos mapas gerados, um mapa registrando as diferenças entre a demanda de irrigação real necessária (demanda total) e de irrigação suplementar real necessária (demanda suplementar) a fim de se verificar a conveniência de incluir ou não, no projeto do sistema de irrigação, a contribuição das precipitações; esse mapa é resultado do overlay (opção diferença) entre os mapas de demanda de irrigação real necessária e de irrigação suplementar real necessária e contabiliza a economia de água proporcionada pelas chuvas, em $\mathrm{mm}$.
Com o objetivo de se estimar o custo (apenas da energia) da não consideração da contribuição das precipitações no manejo do sistema utilizaram-se, como base de cálculo, os pressupostos adotados no trabalho de Carvalho, 1995 (exceto preço da energia). Considerou-se um sistema de irrigação por aspersão com altura manométrica total de $539,55 \mathrm{kPa}$, vazão da motobomba de $1 \mathrm{~L} \mathrm{~s}^{-1} \mathrm{ha}^{-1}$, eficiência da motobomba de $60 \%$, eficiência do sistema de irrigação de $70 \%$ e potência instalada (acréscimo) de $20 \%$. O custo de energia fornecido pela concessionária de energia elétrica (CEMIG) para o mês de julho/98, foi de R $\$ 77,85 \mathrm{MW} \mathrm{h}^{-1}$. Segundo Carvalho (1995), o custo de energia para aplicação de $1 \mathrm{~m}^{3}$ de água obtido utilizando-se os dados característicos do sistema, totalizou um consumo de $0,582 \mathrm{~kW} \mathrm{~m}^{-3}$; assim, para cada metro cúbico de água consumido a mais no ciclo da cultura do milho, contabilizou-se um custo de R $\$ 0,0453$ (considerando-se apenas o custo da energia). Tendo-se como referência a data de plantio respectiva ao menor valor de consumo de água do ciclo ao longo do ano (considerando-se a irrigação suplementar e o solo de textura média), obteve-se o consumo de água no ciclo ao longo do ano para a irrigação total; por outro lado, espacializando-se os dados de consumo suplementar e total de cada localidade (a partir da mesma rotina de cálculo dos mapas em $\mathrm{mm} \mathrm{d}^{-1}$ ) e se utilizando o módulo "overlay" (operação de mapas com opção subtração) obteve-se o mapa da diferença de consumo por ciclo $\left(\mathrm{mm} \mathrm{ciclo}^{-1}\right)$. É importante ressaltar que esta diferença é para condição ótima do ano, relativamente ao consumo de água da planta por ciclo. Desta forma, para cada estação há uma data de plantio e uma duração do ciclo do milho específico, segundo as condições climáticas do local; multiplicando-a por R $\$ 0,0453$ e por 10 (fator de conversão de $\mathrm{mm}$ para $\mathrm{m}^{3} \mathrm{ha}^{-1}$ ) gerou-se o mapa temático, que representa a economia de energia - $\mathrm{R} \$ \mathrm{ha}^{-1}$ ciclo $^{-1}$, cujo valor representa o valor da economia de energia que o agricultor teria se, na época mais favorável para o ciclo da cultura, manejasse adequadamente o sistema de irrigação considerado padrão.

Para melhor compreensão do processamento dos dados climáticos em mapas digitais e da estimativa da economia de água e energia em projetos de irrigação suplementar da cultura do milho para o Estado de Minas Gerais apresenta-se na Figura 1 o fluxograma da geração das imagens.
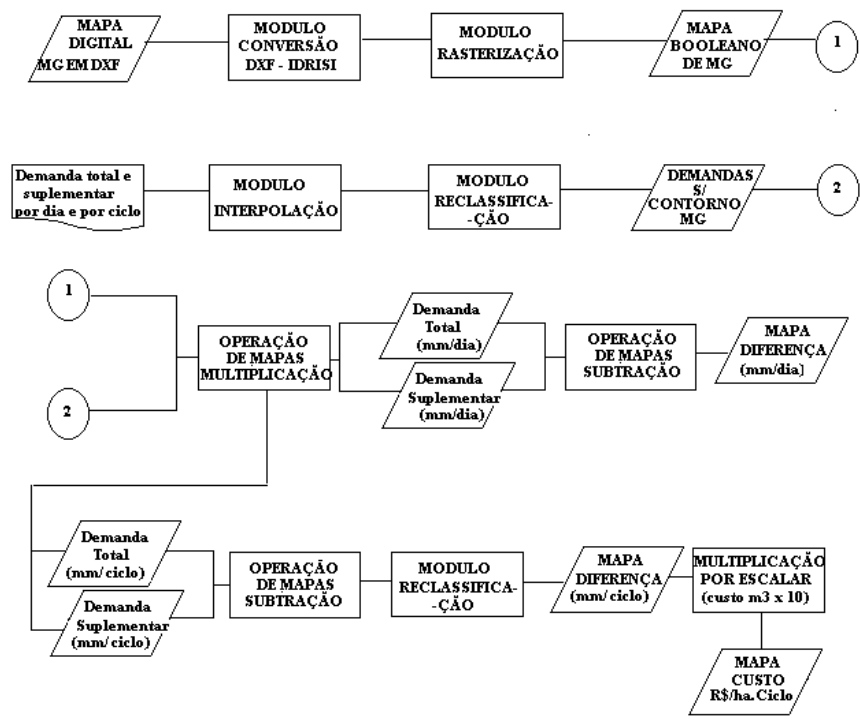

Figura 1. Fluxograma da geração das imagens para análise 


\section{RESULTADOS E DISCUSSÃO}

As diferenças entre as demandas máximas de irrigação real necessária e de irrigação suplementar real necessária para a cultura do milho, com plantio ao longo de todo o ano, no Estado de Minas Gerais, são apresentadas na Figura 2, respectivamente, para os solos de textura grossa (A), média (B) e fina (C).

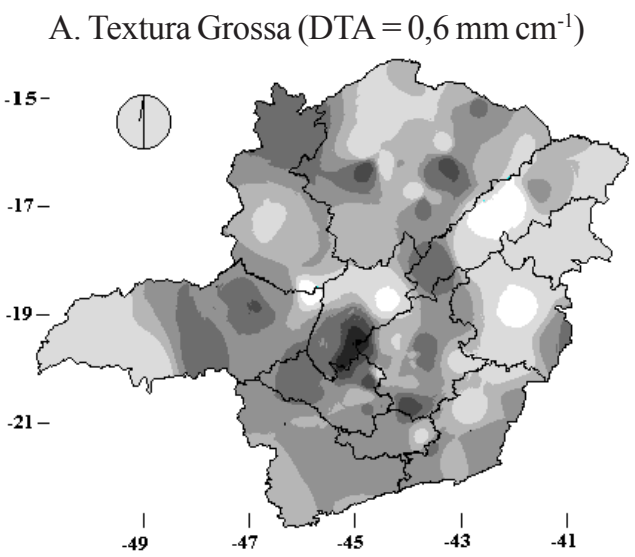

B. Textura Média $\left(\mathrm{DTA}=1,2 \mathrm{~mm} \mathrm{~cm}^{-1}\right)$
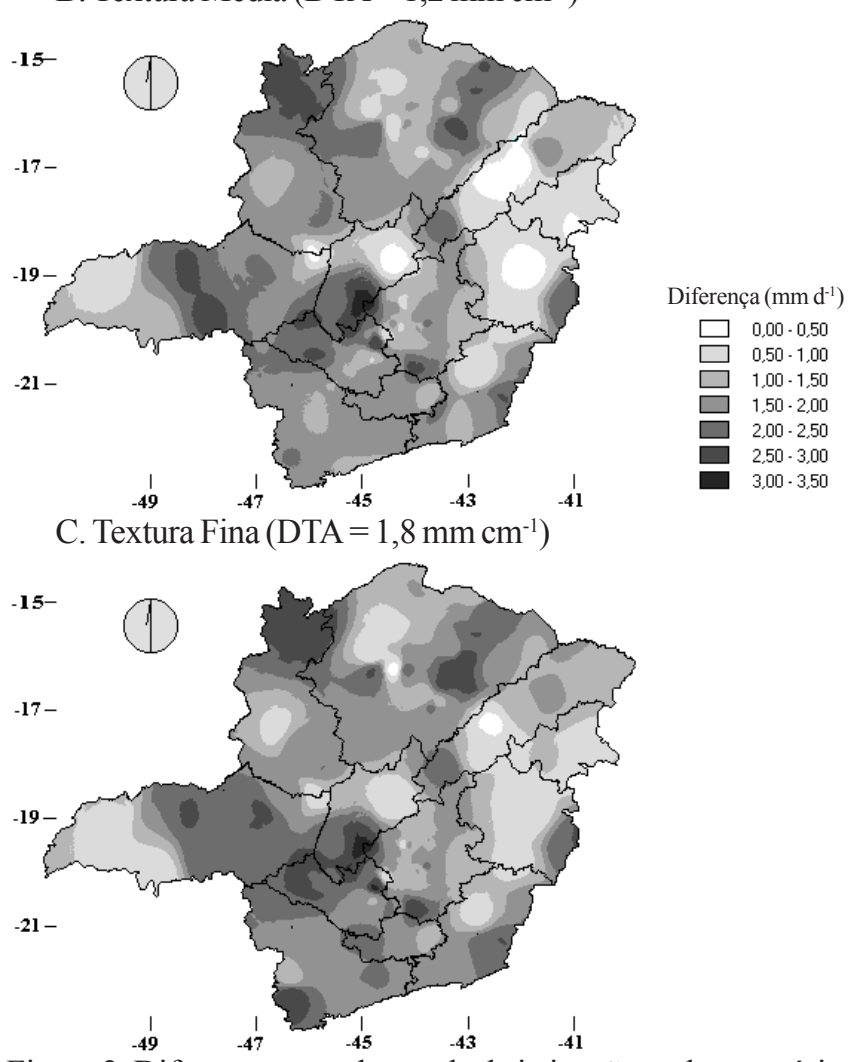

Figura 2. Diferença entre demanda de irrigação real necessária e de irrigação suplementar real necessária, em solos de diferentes texturas

As áreas acumuladas conforme as classes de diferença entre a irrigação real necessária e a irrigação suplementar real necessária, são apresentadas na Tabela 1, para os solos de textura grossa, média e fina.

Analisando-se os dados da Tabela 1 concomitante com a Figura 2 (A, B e C), constata-se que, para expressiva área do Estado de Minas Gerais, a diferença de demandas total e
Tabela 1. Ocupação de área (\%), com as classes de diferença em $\mathrm{mm} \mathrm{d}^{-1}$, entre a demanda de irrigação real necessária e a de irrigação suplementar real necessária, para os solos de textura $\operatorname{grossa}(\mathrm{G})$, média $(\mathrm{M})$ e fina $(\mathrm{F})$

\begin{tabular}{|c|c|c|c|c|c|c|}
\hline \multirow{4}{*}{$\begin{array}{l}\text { Diferença } \\
\text { Demanda } \\
\left(\mathrm{mm} \mathrm{d}^{-1}\right)\end{array}$} & \multicolumn{6}{|c|}{ Área } \\
\hline & \multicolumn{2}{|c|}{ Grossa (G) } & \multicolumn{2}{|c|}{ Média (M) } & \multicolumn{2}{|c|}{ Fina $(F)$} \\
\hline & Classe & Acum* & Classe & Acum* & Classe & Acum* \\
\hline & \multicolumn{6}{|c|}{$\%$} \\
\hline $0,0-0,5$ & 3,31 & 3,31 & 3,6 & 3,57 & 0,04 & 0,04 \\
\hline $0,5-1,0$ & 24,90 & 28,15 & 16,4 & 19,97 & 16,60 & 16,64 \\
\hline $1,0-1,5$ & 25,50 & 53,66 & 24,7 & 44,70 & 23,40 & 40,09 \\
\hline $1,5-2,0$ & 29,80 & 83,48 & 32,5 & 77,16 & 31,20 & 71,34 \\
\hline $2,0-2,5$ & 14,50 & 97,94 & 17,4 & 94,60 & 20,90 & 92,27 \\
\hline $2,5-3,0$ & 1,53 & 99,47 & 5,1 & 99,69 & 7,470 & 99,74 \\
\hline $3,0-3,5$ & 0,53 & 100,00 & 0,3 & 100,00 & 0,26 & 100,00 \\
\hline
\end{tabular}

suplementar situa-se abaixo de uma lâmina hídrica de $1,5 \mathrm{~mm} \mathrm{~d}^{-1}$ (53,66\% no solo $\mathrm{G}, 44,70 \%$ no solo $\mathrm{M}$ e 40,09\% no solo $\mathrm{F}$ ) indicando a contribuição das precipitações nos projetos de irrigação elaborados para essas regiões. Em parte do Triângulo, Noroeste e Centro do Estado, tais diferenças estão acima de $2,0 \mathrm{~mm} \mathrm{~d}^{-1}(16,52 \%$ no solo $\mathrm{G}, 22,84 \%$ no solo $\mathrm{M}$ e $28,66 \%$ no solo F) tornando-se altamente interessante levar-se em conta, nessas áreas, a economia propiciada pelas chuvas no dimensionamento do sistema de irrigação. As regiões que não apresentaram a possibilidade de utilizar a contribuição natural das chuvas na dotação dos projetos de irrigação, são quase inexpressivas, ocupando apenas 3,31\% da área do Estado, no solo de textura grossa e $0,04 \%$ no solo de textura fina, localizadas principalmente no nordeste de MG. Independentemente do tipo de solo, observa-se que as classes de diferença no intervalo entre 0,5 a 2,5 $\mathrm{mm} \mathrm{d}^{-1}$ ocupam a maior área do Estado e o solo de textura fina apresenta a distribuição mais uniforme de classes nesse intervalo, considerando-se as áreas que cada uma ocupa.

Coerentemente, constatou-se que o solo de textura fina apresenta áreas mais extensas para diferenças acima de $1,5 \mathrm{~mm} \mathrm{~d}^{-1}$ em comparação com os mapas relativos aos outros dois solos, o que se deve ao fato deste solo apresentar maior disponibilidade total de água, resultando na necessidade de irrigações menos freqüentes; neste sentido, a possibilidade de se aumentar a economia na dotação de água, em projetos desenvolvidos em solos de textura fina, é maior que para os outros tipos de solo. Os métodos de irrigação que utilizam alta freqüência na aplicação da água (turno de rega pequeno) como o pivô central e a irrigação localizada, são mais adequados para irrigação em solo de textura grossa.

As classes acumuladas em \% para os três tipos de solo apresentados na Tabela 1, foram agrupadas no gráfico correspondente à Figura 3.

Observa-se, na Figura 3, que o solo de textura média apresentou comportamento mais próximo ao solo de textura fina que o solo de textura grossa, comparativamente. Ressaltase o padrão uniforme da diferença entre os solos uma vez que as retas que unem os pontos têm praticamente a mesma inclinação. Os limites inferior e superior encontrados para as diferenças entre a demanda de irrigação total real necessária e a de irrigação suplementar real necessária para os três tipos 


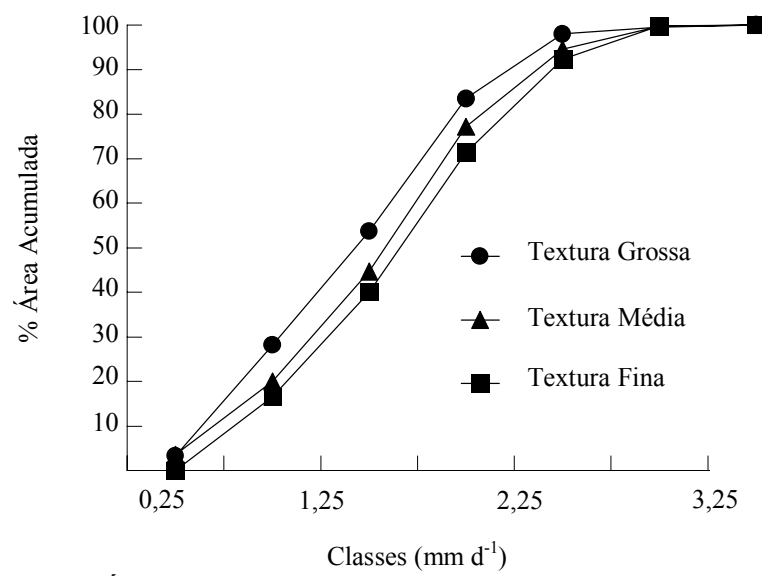

Figura 3. Áreas ocupadas acumuladas, em \%, das classes de diferença, em mm, entre a demanda de irrigação real necessária e a de irrigação suplementar real necessária, para os solos de textura grossa, média e fina

de solo considerados, são em torno de $0,25 \mathrm{~mm}$ e $2,75 \mathrm{~mm}$. Independentemente do tipo de solo, metade do Estado de Minas Gerais (50\% da área acumulada) apresentou uma diferença entre as demandas consideradas em torno de $1,25 \mathrm{~mm}$; esta diferença, considerando-se a época mais favorável do ano, em mm ciclo ${ }^{-1}$, entre as demandas de irrigação real necessária e de irrigação suplementar real necessária para o solo de textura média, é apresentada na Figura 4.

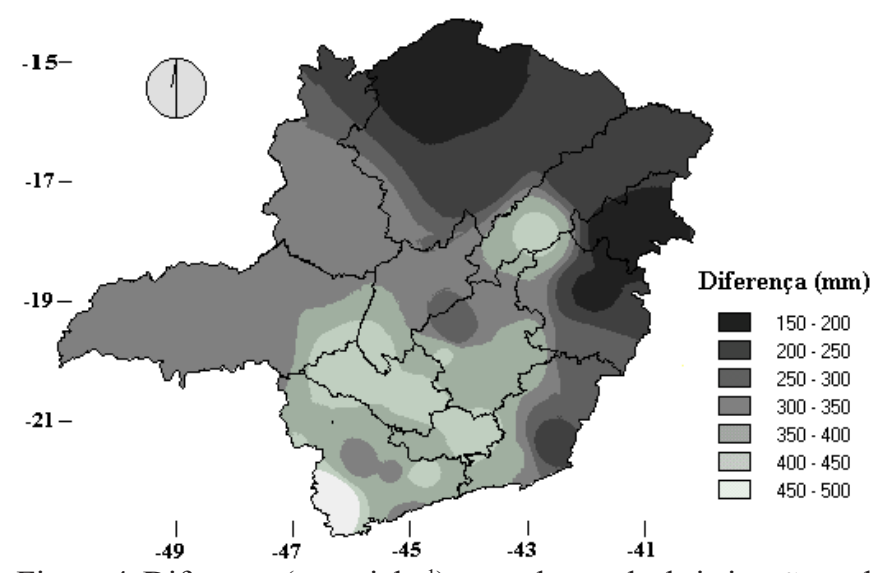

Figura 4. Diferença $\left(\mathrm{mm} \mathrm{ciclo}^{-1}\right)$ entre demanda de irrigação real necessária e de irrigação suplementar real necessária para solo de textura média, considerando-se o ciclo mais favorável para a cultura

Multiplicando-se as diferenças indicadas na Figura 4 por 10 (para converter $\mathrm{mm}$ para gasto de água $\mathrm{em} \mathrm{m}^{3} \mathrm{ha}^{-1}$ ) e pelo custo da energia ( $\mathrm{R} \$$ por $\mathrm{m}^{3}$ de água economizado no ciclo) gera-se o mapa da Figura 5, que representa a economia de energia $\left(\mathrm{R} \$ \mathrm{ha}^{-1}\right)$ durante o ciclo (considerando-se a época mais favorável do ano em solo de textura média). É importante recordar que a data de plantio que otimiza a contribuição das chuvas e a duração do ciclo do milho depende, das condições climáticas da localidade considerada.

Observa-se, no mapa da Figura 5, três áreas que se destacam pela superfície que abrangem, localizadas (em ordem crescente de economia) no norte ( $\mathrm{R} \$ 80$ a $\left.120 \mathrm{ha}^{-1}\right)$, centro-oeste ( $\mathrm{R} \$ 120$ a 160 ha $^{-1}$ ) e sul (R $\$ 160$ a 200 ha $\left.^{-1}\right)$ ocupando 36, 40 e 23\% da área total do Estado de Minas Gerais, respectivamente, e se constata que sempre haverá, mesmo nas regiões quentes, a possibilidade de se utilizar as precipitações como meio de diminuir os gastos de funcionamento do sistema de irrigação na época mais favorável para a cultura; coerentemente, as regiões mais quentes e menos chuvosas (como do norte e nordeste) são aquelas que apresentam menores diferenças entre irrigação suplementar e total; assim, a possível economia de energia elétrica, levando-se em consideração a contribuição das chuvas, será bem menor que nas regiões mais ao sul do Estado, onde há regiões em que a economia poderá chegar a até $\mathrm{R} \$ 240$ por ciclo da cultura. Reafirma-se que os valores de diferença de consumo para os tipos de irrigação (suplementar e total) são para condições de clima extremamente favoráveis para a cultura durante o ciclo e os resultados são válidos somente para o sistema de aspersão padrão considerado. Não observadas as condições específicas de clima do sistema de cada localidade, o agricultor será um potencial desperdiçador de energia e água, podendo comprometer o desenvolvimento auto-sustentado do seu empreendimento.

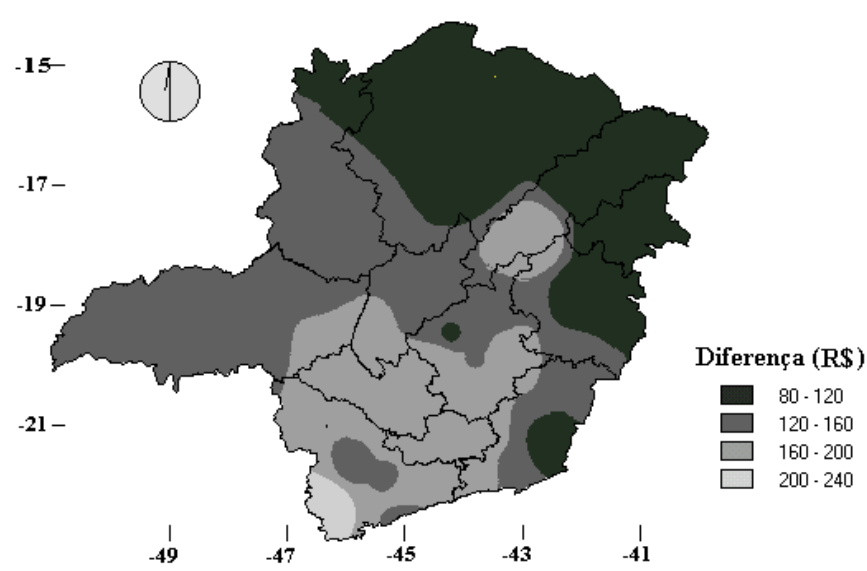

Figura 5. Economia de energia $\left(\mathrm{R} \$ \mathrm{ha}^{-1}\right)$ durante o ciclo, considerando a época mais favorável do ano em solo de textura média

\section{CONCLUSÕES}

Com base nos resultados obtidos, concluiu-se que:

1. Os limites inferior e superior encontrados para as diferenças entre a demanda de irrigação total real necessária e a de irrigação suplementar real necessária para os três tipos de solo considerados, são em torno de 0,25 e 2,75 mm.

2. As regiões que não apresentaram a possibilidade de utilizar a contribuição natural das chuvas na dotação dos projetos de irrigação são quase inexpressivas.

3. Independentemente do tipo de solo, observa-se que as classes de diferença no intervalo entre 0,5 a $2,5 \mathrm{~mm} \mathrm{~d}^{-1}$ ocupam a maior área do Estado sendo que, metade do Estado apresentou uma diferença entre as demandas total e suplementar, em torno de $1,25 \mathrm{~mm}$.

4. Para expressiva área do Estado de Minas Gerais, as diferenças de demandas total e suplementar situam-se abaixo de uma lâmina hídrica de $1,5 \mathrm{~mm} \mathrm{~d}^{-1}$, entretanto em parte do 
Triângulo, Noroeste e Centro do Estado, tais diferenças estão acima de $2,0 \mathrm{~mm} \mathrm{~d}^{-1}$ tornando-se interessante considerar-se, nessas áreas, a economia propiciada pelas chuvas no dimensionamento do sistema.

5. O mapa que estima a economia de energia $\left(\mathrm{R} \$ \mathrm{ha}^{-1}\right)$ durante o ciclo apresenta áreas localizadas (em ordem crescente de economia) no norte, centro-oeste e sul.

\section{LITERATURA CITADA}

Assis, F.N.; Arruda, H.V.; Pereira, A.R. Aplicações de estatística à climatologia: teoria e prática. Pelotas: UFPel, 1996. 161p.

Bernardo, S. Manual de irrigação. 6. ed. Viçosa: UFV, 1995. $657 \mathrm{p}$.

Carvalho, J.A.; Bernardo, S.; Casali, V.W. Análise econômica da produção de cenoura (Daucus carota L.) irrigada. Engenharia na Agricultura, Viçosa, v.4, n.45, p.1-4, 1995.
Coelho, D.T. The consideration of temperature in corn ( $\mathrm{Zea}$ mays L.) growth and development models. West Lafayette: Purdue University, 1978. 70p. PhD Thesis

Doorenbos, J.; Pruitt, W.O. Guidelines for predicting crop water requirements. Rome: FAO, 1977. 144p. Irrigation and Drainage Paper, 24

Eastman, J.R. IDRISI technical reference. Massachusetts: Clark University, 1992.213p.

Hashmi, M.A.; Garcia, L.A.; Fontane, D.G. Spatial estimation of regional crop evapotranspiration. Transactions of the ASAE, St. Joseph, v.38, n.5, p.1345-1351, 1995.

Smith, M. Report on the expert consultation on revision of FAO methodologies for crop water requirements. Rome: FAO, 1991. 45p

Souza, E.F. Modelo computacional aplicado ao manejo e planejamento de irrigação. Viçosa: UFV, 1993. 65p. Dissertação Mestrado 